\title{
Strong geographical variation in wing aspect ratio of a damselfly, Calopteryx maculata (Odonata: Zygoptera)
}

Christopher Hassall

Geographical patterns in body size have been described across a wide range of species, leading to the development of a series of fundamental biological rules. However, shape variables are less well-described despite having substantial consequences for organism performance. Wing aspect ratio (AR) has been proposed as a key shape parameter that determines function in flying animals, with high AR corresponding to longer, thinner wings that promote high manoeuvrability, low speed flight, and low AR corresponding to shorter, broader wings that promote high efficiency long distance flight. From this principle it might be predicted that populations living in cooler areas would exhibit low AR wings to compensate for reduced muscle efficiency at lower temperatures. I test this hypothesis using the riverine damselfly, Calopteryx maculata, sampled from 34 sites across its range margin in North America. Nine hundred and seven male specimens were captured from across the 34 sites (mean=26.7 \pm 2.9 SE per site), dissected and measured to quantify the area and length of all four wings. Geometric morphometrics were employed to investigate geographical variation in wing shape. The majority of variation in wing shape involved changes in wing aspect ratio, confirmed independently by geometric morphometrics and wing measurements. There was a strong negative relationship between wing aspect ratio and the maximum temperature of the warmest month which varies from west-east in North America, creating a positive relationship with longitude. This pattern suggests that higher aspect ratio may be associated with areas in which greater flight efficiency is required: regions of lower temperatures during the flight season. I discuss my findings in light of research of the functional ecology of wing shape across vertebrate and invertebrate taxa. 
1 Strong geographical variation in wing aspect ratio of a damselfly, Calopteryx

4 Author: Christopher Hassall

5 Address: School of Biology, University of Leeds, Leeds, LS2 3JT, United Kingdom

6 Telephone: +4401133435578

$7 \quad$ Fax: +4401133433091

8 Running title: Damselfly wing morphology 


\section{ABSTRACT}

10 Geographical patterns in body size have been described across a wide range of species, leading to the

11 development of a series of fundamental biological rules. However, shape variables are less well-described

12 despite having substantial consequences for organism performance. Wing aspect ratio (AR) has been

13 proposed as a key shape parameter that determines function in flying animals, with high AR

14 corresponding to longer, thinner wings that promote high manoeuvrability, low speed flight, and low AR

15 corresponding to shorter, broader wings that promote high efficiency long distance flight. From this

16 principle it might be predicted that populations living in cooler areas would exhibit low AR wings to

17 compensate for reduced muscle efficiency at lower temperatures. I test this hypothesis using the riverine

18 damselfly, Calopteryx maculata, sampled from 34 sites across its range margin in North America. Nine

19 hundred and seven male specimens were captured from across the 34 sites (mean=26.7 \pm 2.9 SE per site),

20 dissected and measured to quantify the area and length of all four wings. Geometric morphometrics were

21 employed to investigate geographical variation in wing shape. The majority of variation in wing shape

22 involved changes in wing aspect ratio, confirmed independently by geometric morphometrics and wing

23 measurements. There was a strong negative relationship between wing aspect ratio and the maximum

24 temperature of the warmest month which varies from west-east in North America, creating a positive

25 relationship with longitude. This pattern suggests that higher aspect ratio may be associated with areas in

26 which greater flight efficiency is required: regions of lower temperatures during the flight season. I

27 discuss my findings in light of research of the functional ecology of wing shape across vertebrate and

28 invertebrate taxa.

29

30 Keywords: wing morphology, aspect ratio, flight, dispersal, range, damselfly, Odonata. 


\section{INTRODUCTION}

Powered flight has evolved independently in four different lineages: the pterosaurs, insects, birds, and bats, allowing animals to exploit novel niches and avoid predators. The adaptations that allowed each of these transitions to an aerial niche represent a suite of similar traits that can be broken down into a number of functional morphological components that influence inter- and intraspecific variation in flight performance. First, absolute body size is correlated with dispersal ability across a wide range of taxa (Jenkins et al. 2007). Second, the ratio of body mass to wing area - known as "wing loading" - has a strong influence on the amount of thrust generated per wingbeat (Dudley 2002). However, for the purposes of this study I am most interested in the third component of variation: that of wing shape. One of the principle measures of functional variation in wing shape is the length of the wing relative to the width, known as aspect ratio. In vertebrates, higher aspect ratio (longer, thinner wings) is predicted to give faster and more efficient flight (Norberg 1989) and has been shown to be associated with migratory species in birds (Mönkkönen 1995). However, there has been speculation that the benefits of high aspect ratio may be reduced or even reversed at the low Reynolds numbers (a measure of aerodynamic turbulence, with lower numbers corresponding to the viscous forces experienced by small objects) experienced by insects (Ennos 1989; Wootton 1992). This speculation, along with the difference in the nature of flight - number, structure and locomotory independence of wings - between birds and insects complicates the formation of hypotheses concerning the implications of variation in flight morphology (Betts \& Wootton 1988; Johansson et al. 2009). The literature on the functional relevance of insect wing morphology is heavily biased towards theory (Dudley 2002), laboratory studies (Betts \& Wootton 1988; Marden 1995) and observations of kinematics (Rüppell 1989; Wakeling \& Ellington 1997a, b, c) rather than quantitative data collected from the field.

Contrary to predictions for birds, where higher aspect ratios are associated with higher flight speeds (Alerstam et al. 2007), a number of findings point towards lower wing aspect ratio as being beneficial for dispersal in insects. Wing aspect ratio is lower in populations of Pararge aegeria that have recently been 
founded (Hill et al. 1999). Populations of P. aegeria (Hughes et al. 2007; Vandewoestijne \& Van Dyck 2011), Drosophila melanogaster (Azevedo et al. 1998), and a number of damselflies (Hassall et al. 2009; Taylor \& Merriam 1995) show lower aspect ratio at higher latitudes where temperature reduces the efficiency of flight in ectotherms. This reduction in flight power at lower temperatures has been demonstrated in a number of laboratory systems (Lehmann 1999) and is likely related to lower wingbeat frequencies at lower temperatures (Dudley 2002). Since lower wing aspect ratios are associated with greater dispersal ability, it could be that a decline in aspect ratio compensates for this decline in wingbeat frequency (Stalker 1980). Other studies have shown higher wing aspect ratio only in species of damselflies with expanding range margins (Hassall et al. 2009), and those marginal populations exhibit wing shapes that deviate progressively away from the species average closer to the range margin (Hassall et al. 2008). Studies using common garden rearing of Drosophila from a range of latitudes have shown that individuals reared at lower temperatures have lower aspect ratio (Azevedo et al. 1998). While there is no clear relationship between aspect ratio and flight speed in butterflies (Berwaerts et al. 2008; but cf Berwaerts et al. 2002; Dudley 1990), species in which males "patrol" (i.e. exhibit prolonged flight) tend to have lower aspect ratios (Wickman 1992). Chironomid females have broader wings (characteristic of lower aspect ratio) to assist with flying for long periods between habitat patches (McLachlan 1986). While there are exceptions (increased fragmentation does not correlate with aspect ratio in Plebejus argus (Thomas et al. 1998) or Pararge aegeria (Merckx \& Van Dyck 2006)) these findings seem to suggest that lower wing aspect ratio in insects is associated with greater dispersal.

Odonata have been shown to be sensitive to temperature in a number of life history traits (Hassall \& Thompson 2008) and are responding to climate change by advancing phenology (Hassall et al. 2007) and expanding their ranges poleward (Hassall \& Thompson 2010; Hickling et al. 2006). As a result, odonates would be expected to follow the same geographical patterns as those described above: a decrease in wing aspect ratio to compensate for low wingbeat frequencies at low temperatures (as seen in Diptera), and a further decrease if the species is expanding its range (as seen in Lepidoptera). Wing morphology in 
83 Odonata may also be affected by a combination of sexual selection during intrasexual, agonistic 84 interactions, intersexual courtship displays and dispersal (Johansson et al. 2009). In the field, intrasexual 85 territorial contests in Calopteryx maculata are determined by fat reserves (Marden \& Rollins 1994; 86 Marden \& Waage 1990) and contests in Plathemis lydia are determined by flight muscle ratio (Marden 87 1989). In both cases, aspect ratio was shown not to influence the outcome of the contests. Sexual 88 selection on courtship displays focuses on patterns of pigmentation in Calopteryx species (Siva-Jothy 89 1999; Waage 1973). However, wing shape has been shown to vary with landscape structure in $C$.

90 maculata (Taylor \& Merriam 1995) and between some closely-related species of Calopterygidae in

91 Europe (Sadeghi et al. 2009), although not all species exhibited distinct wing shapes. Based on these

92 results, it seems that wing shape variation is under natural selection due to dispersal (within or between 93 sites), rather than sexual selection.

94

95 Based on the reasoning presented above, I evaluate the hypothesis that, a positive relationship would be 96 found between temperature and aspect ratio to compensate for lower flight efficiency at lower 97 temperatures. Uncertainties over the ecological role of morphology variation may stem from the partial sampling of geographical ranges (Hassall 2013). Limited sampling of non-linear trends that occur over

99 large spatial scales may produce misleading results and so I provide an analysis of wing shape variation 100 across almost the entire range of the damselfly Calopteryx maculata in North America. 
102 A total of 907 specimens of male C. maculata were collected from 34 sites across the range by 25

103 collectors (Figure 1, Table 1). Collections took place between 13 May and 7 August 2010 and mean

104 sample size from each site varied between 4 and 84 individuals (mean=26.7 $\pm 2.9 \mathrm{SE}$, details of sample

105 sizes and mean measurements can be found in Table 1). Wings were dissected from the body as close to

106 the thorax as possible and mounted on adhesive tape (Scotch Matte Finish Magic Tape). Wings were

107 scanned using the slide scanner on an Epson V500 PHOTO flatbed scanner with fixed exposure at

108 1200dpi. Wing length (the length from the costal end of the vein separating the arculus from the discoidal

109 cell to the tip of the wing) and wing area were calculated for each of the four wings on each individual.

110 All measurements were carried out in ImageJ (Rasband 1997-2007). During measurement, any damage to

111 wings was noted and those measurements (length or area) which could not be accurately quantified were

112 excluded. This resulted in the exclusion of 7 fore wing and 9 hind wing lengths, and 28 fore wing and 45

113 hind wing areas. Aspect ratio was then calculated separately for both fore and hind wings as

114 wingspan $2 /$ wing area (see Table 1 for summary statistics and sample sizes). Raw data for measurements

115 can be found in Table S1.

117 It has been suggested that wing aspect ratio does not provide sufficient detail to be morphologically 118 informative in butterflies (Betts \& Wootton 1988) or dragonflies (Johansson et al. 2009). Therefore, in 119 addition to calculating aspect ratio, I also use geometric morphometrics to derive descriptors of the shape 120 of the wing. A subset of up to 10 individuals from each site were selected at random and a set of 14 121 landmarks were digitised on 1 fore wing and 1 hind wing (Figure 2) using tpsDig2 (v.2.12, Rohlf 2008).

122 Mean locations for each of the 14 landmarks were found for each of the 34 sites. Principal components 123 analysis (PCA) was carried out on these landmarks after Procrustes transformation (to correct for 124 differences in size and rotation of the wing, leaving only shape variation) using the PAST software 125 package (Hammer et al. 2001). Relationships between the principal components and absolute 126 measurements were investigated using Pearson correlations. Fore and hind wings were compared using 
127 paired Hotelling's t ${ }^{2}$ tests in PAST to assess whether the two datasets could be combined. Raw data for

128 fore and hind wing geometric morphometric landmarks can be found in Tables S2 and S3, respectively.

129

130 Bioclim temperature variables (BIO1-BIO11) were extracted for each site from the WORLDCLIM

131 dataset (Haylock et al. 2008) to test the central hypothesis of the study. A large number of candidate

132 variables exist that could be included (11 Bioclim variables, and mean, minimum and maximum

133 temperature for each month). Monthly temperature variables were ignored, as Bioclim variables are more

134 likely to have greater biological relevance. Bioclim variables were subjected to model selection with each

135 of the 11 variables regressed against fore and hind wing aspect ratio and the best-fitting variable selected

136 using Akaike's information criterion (AIC). Aspect ratio and the informative principal components from

137 the shape analysis were regressed against temperature, latitude, and longitude using linear regressions

138 weighted by the square-root of the sample size. In each case, the models were tested with a quadratic

139 predictor term using AIC to evaluate any improvement in model fit. 


\section{RESULTS}

141 Fore and hind wings vary significantly in shape $\left(\mathrm{t}^{2}=122500, \mathrm{p}<<0.001\right)$ and were completely separated 142 along the PC1 axis which explained $80.2 \%$ of the variance in shape. As a result, fore and hind wing data 143 are treated separately for the rest of the analysis.

The first three principal components explaining fore and hind wing variation explained $38.7 \%, 23.2 \%$ and $18.6 \%$ (total $80.5 \%$ ) of the variance in fore wing shape and $44.9 \%, 21.4 \%$, and $12.6 \%$ (total $78.9 \%$ ) of the variance in hind wing shape. PC1 in both cases involved a variation in the width of the wing relative to its length, such that an increase in PC1 leads to a decrease in the width of the wing relative to the length (Figure 3). The PC2 and PC3 involved more subtle shape changes which were still consistent between wings. PC2 appears to involve a shortening of the pre-nodal region and a blunting of the tip, while PC3 corresponds to a movement of wing area towards the wing tip. PC1 was significantly positively correlated with aspect ratio (fore wings, $r=0.875, \mathrm{p}<0.001$; hind wings, $\mathrm{r}=0.854, \mathrm{p}<0.001$, Figure 4).

Aspect ratios for fore and hind wings were very highly correlated $(\mathrm{R}=0.978, \mathrm{p}<0.001)$ and so only statistics for fore wings are presented here. Regression of aspect ratio on latitude showed a substantially improved fit when the quadratic term was included (linear $\mathrm{AICc}=-3.4$; quadratic $\mathrm{AICc}=-10.5$; $\Delta \mathrm{AICc}=7.1$ ). Regression of aspect ratio on longitude showed no improvement in fit when the quadratic term was included (linear $\mathrm{AICc}=-35.2$; quadratic=-32.7; $\triangle \mathrm{AICc}=2.5$ ). The Bioclim temperature variables that best predicted fore wing aspect ratio were Bio5 (maximum temperature of the warmest month, top model) and Bio2 (mean diurnal temperature range, $\triangle \mathrm{AIC}=1.27$ ). All other variables produced models with $\triangle \mathrm{AIC}>10$ relative to the top model indicating negligible relative explanatory power (Table 2). Bio5 was selected as the temperature variable, as Bio5 models produced greater average support $(\triangle \mathrm{AIC}=0$, $\Delta \mathrm{AICc}=0.54)$ than $\mathrm{Bio} 2(\Delta \mathrm{AICc}=0, \Delta \mathrm{AICc}=1.27)$, and represents a measure of absolute temperature

164 (maximum temperature of the warmest month) rather than variability (mean diurnal range), which is 165 closer to the initial hypothesis for the relationship between temperature and aspect ratio. The addition of a 
quadratic term did not improve the fit of a regression model describing the relationship between aspect

167 ratio and Bio5 (linear $\mathrm{AIC}=-18.7$; quadratic $\mathrm{AIC}=-16.2 ; \Delta \mathrm{AIC}=2.5$ ).

168

169 Geographical patterns of wing aspect ratio showed a complex spatial pattern (Figure 5). There was a U-

170 shaped relationship between aspect ratio and latitude (Table 3; Figure 6A), explaining 32.5\% of the

171 variation in the data. However, this may be due to the distribution of sites (Figure 5), with most of the

172 mid-latitude sites being found inland in continental areas while northern and southern sites tended to be

173 closer to the coast where temperatures are cooler (Figure 1B). Indeed, the linear, positive relationship

174 with longitude (Table 3; Figure 6B), indicating a decline in aspect ratio further west, explained $66.0 \%$ of

175 the variation in the data. Aspect ratio was also significantly negatively related to Bio5, which explained

$17644.6 \%$ of the variability in the data (Table 3, Figure 6C). When the three models were compared, the

177 longitude model explained by far the greatest proportion of the data (Akaike weight $\approx 1$; Table 3).

178 However, the geographical distribution of aspect ratio values (Figure 5, Figure 6B) suggests that there

179 may be a step-change in wing shape at a certain longitude, rather than a gradual trend. 


\section{DISCUSSION}

181 I provide the first comprehensive assessment of intraspecific variation in wing morphology across almost

182 an entire range in a damselfly. The use of geometric morphometrics to analyse shape confirms that 183 changes in aspect ratio (i.e. changes in the length of the wing relative to the width) constitute the major 184 source of variation between specimens from different sites. I demonstrate a highly significant relationship 185 between temperature (the maximum temperature of the warmest month) and fore wing shape, with higher 186 wing aspect ratios at lower temperatures. The dominant geographical pattern is one of increasing aspect 187 ratio from west to east, which has not been documented in previous studies and may be related to lower 188 maximum temperatures in the western part of the range. A weaker pattern appears to be present with 189 latitude, where there is evidence of higher aspect ratio at the northern and southern range margins.

190

191 The literature on the functional relevance of aspect ratio has produced conflicting findings, but the present study offers some insights into this phenomenon that are consistent with previous studies in odonates. The presence of higher aspect ratio wings in regions that experience lower temperatures and at range margins is consistent with previous studies that found higher aspect ratios in cases where flight was more demanding. For example, higher aspect ratios have been associated with populations of calopterygid damselflies inhabiting fragmented habitat (Taylor \& Merriam 1995) and at the expanding edge of the geographical range (Hassall et al. 2009). Models predict that improved dispersal should evolve at range margins in response to lower habitat persistence or range expansion (Travis \& Dytham 1999), and these predictions are supported by observations in butterflies (Hill et al. 1999). However, due to the observational nature of this study I cannot disentangle the effects of selection from those of phenotypic plasticity. Indeed, previous studies have demonstrated that while some flight morphological parameters are under genetic control, wing aspect ratio shows a plastic response to the environment in Drosophila

203 (Azevedo et al. 1998). Note that while this study found evidence for a U-shaped relationship between

204 latitude and aspect ratio, the western range margin appears to be associated with very low aspect ratio 205 which is inconsistent with the range margin being associated with high aspect ratio wings. Indeed, the 
presence of the U-shaped relationship is more likely to be an artefact of the arrangement of sampling sites: the southern sites also tend to be in the eastern part of the range where the aspect ratio is highest (Figure 5). If it is maximum summer temperature that is driving the variation in wing shape then it might be predicted that there would be little latitudinal pattern in aspects ratio, as maximum summer temperature does not vary consistently with latitude (Figure 1B). Instead, the temperature variation in the summer tends to be associated with inland vs. coastal areas, with cooler climates in regions closer to the oceans. This coastal buffering of maximum summer temperature, even operating at a scale of $100 \mathrm{~s}$ of $\mathrm{km}$ (shown in Figure 1B), provides a potential explanation of the relationship between longitude and wing 214 shape.

It is generally considered that higher aspect ratios provide a benefit for longer-distance flight (Mönkkönen 1995), efficient, gliding flight (Ennos 1989), and flight at lower temperatures (Azevedo et al. 1998). A mechanism for this pattern might be provided by Marden's (1987) observation that wing aspect ratio is negatively related to lift production (controlling for body mass and flight muscle ratio) in conventional wingbeats, but that this is reversed in the case of clap-and-fling wingbeats of the sort used by Calopterygidae. Hence higher aspect ratios generate more lift in Calopteryx sp. which would enhance flight efficiency. However, this is equivocal in Lepidoptera (Betts \& Wootton 1988) where previous studies have found lower aspect ratio at lower temperatures (Vandewoestijne \& Van Dyck 2011). There remains a gap in the literature that needs to be filled with flight laboratory experiments of the functional implications of aspect ratio variation in odonates and other insects as have been carried out in some butterflies (Berwaerts et al. 2008; Berwaerts et al. 2002; Davis et al. 2012). In particular, a test of the hypothesis that higher variation in aspect ratio can enhance flight efficiency at lower temperatures in odonates is warranted given the increasing evidence for the correlation between aspect ratio and temperature. 
231 The association between maximum temperature in the warmest month (which is associated with peaks in

232 emergence in most odonates, Dijkstra \& Lewington 2006) makes sense given the vast quantities of energy

233 expended by insects during this period. Calopteryx males, in particular, compete for and hold territories as

234 well as undertaking extensive aerial contests with competitor males that are energetic wars of attrition

235 (Marden \& Waage 1990; Plaistow \& Siva-Jothy 1996). The small benefit in terms of increased lift from

236 the change in wing shape may benefit males during these activities. However, analysis of these conflicts

237 in Calopteryx virgo showed that there was no difference in aspect ratio between winners and losers (Bots

238 et al. 2012). Given the theoretical benefits and the observed interpopulation variation in aspect ratio, it is

239 surprising that there has not been evolution to a biomechanical optimum across the species. One potential

240 explanation is that aspect ratio is not heritable, but rather is determined by environmental factors as has

241 been shown in Drosophila (Azevedo et al. 1998). It has been proposed that the fore and hind wings of

242 Calopteryx sp. have evolved under natural and sexual selection, respectively (Outomuro et al. 2012), but

243 many studies of this kind have failed to sample from a wide geographical range and so the extent to which

244 the findings of those studies can be generalised is unclear.

246 Previous studies have questioned the use of aspect ratio as a single numerical metric describing wing 247 shape in insects, due to its inability to represent the complexity of wing morphology (Betts \& Wootton 248 1988; Johansson et al. 2009). However, I find that a complex method of shape analysis using geometric morphometrics yields patterns that strongly resemble variation in the simpler concept of aspect ratio. However, it is clear from the explanatory power of those principal components that correlate with aspect ratio $(38.7 \%$ and $44.9 \%)$ that there is a great deal of variability in addition to this dimension. It is worth noting that insects exhibit a great deal of variation in aspect ratio. Odonates have high aspect ratios compared to some other insects, for example Drosophila virilis with an aspect ratio of 2 (Vogel 1957), and Bombus terrestris with an aspect ratio of 6.4. However, butterflies show higher aspect ratios of 9.810.5 in Pararge aegeria (Berwaerts et al. 2008; Berwaerts et al. 2002). The data presented here show aspect ratios of hind wings between 5.61 and 7.79 and of forewings between 5.70 and 7.56. Aeshna 
cyanea, a large odonate, exhibits aspect ratio of 8.4 and 11.6 for hind and fore wings, respectively

258 (Ellington 1984). What makes the odonate wing very different is the extent of the venation in odonate

259 wings compared to other taxa. This venation may be associated with the pleating of the wing, which

260 enhances aerodynamic performance relative to a smooth with of the same shape (Vargas et al. 2008).

261

262 The results presented here demonstrate clear geographical variation in flight morphology in a damselfly

263 across almost its entire range. While the other studies investigating geographical variation in odonate

264 morphology have focused on north-south transects (Johansson 2003), there are clearly important patterns

265 occurring along the east-west axis of the range highlighting the need to consider range-wide surveys to

266 understand macroecological and macroevolutionary patterns (Hassall 2013, 2014). From the survey of

267 studies that have included aspect ratio, it is clear that laboratory studies are needed to clarify the

268 relationship between form and function in odonate wing shape. 


\section{ACKNOWLEDGEMENTS}

270 I am extremely grateful to Arne Iserbyt, Mary Burnham, Chris Lewis, Shari Sokay, Darrin OBrien, Fred

271 Sibley, Giff Beaton, George Harp, George Sims, Harris Luckham, John Abbott, Joseph Carson, Jeni

272 Eggers and Eliott Porter, Jeffrey Willers, Michael Blust, Marion Dobbs, Mark Musselman, Pat Heithaus,

273 Rick Abad, Ryan Spafford, Steve Hummel, Sarah Richer, Timothy Sesterhenn, William Lamp and Wade

274 Worthen for giving so graciously of their time to assist with collections. Carley Centen provided valuable 275 assistance in the field and Tom Langen provided assistance with logistics. 


\section{REFERENCES}

Alerstam T, Rosén M, Bäckman J, Ericson PGP, and Hellgren O. 2007. Flight speeds among bird species: allometric and phylogenetic effects. PLoS Biol 5:e197.

Azevedo RBR, James AC, McCabe J, and Partridge L. 1998. Latitudinal variation of wing:thorax size ratio and wing-aspect ratio in Drosophila melanogaster. Evolution 52:1353-1362.

Berwaerts K, Matthysen E, and Van Dyck H. 2008. Take-off flight performance in the butterfly Pararge aegeria relative to sex and morphology: a quantitative genetic assessment. Evolution 62:2525-2533.

Berwaerts K, Van Dyck H, and Aerts P. 2002. Does flight morphology relate to flight performance? An experimental test with the butterfly Pararge aegeria. Functional Ecology 16:484-491.

Betts CR, and Wootton RJ. 1988. Wing shape and flight behaviour in butterflies (Lepidoptera:

Papilionoidea and Hesperioidea): a preliminary analysis. Journal of Experimental Biology 138:271-288.

Bots J, Breuker CJ, Kaunisto KM, Koskimäki J, Gossum HV, and Suhonen J. 2012. Wing shape and its influence on the outcome of territorial contests in the damselfly Calopteryx virgo. Journal of Insect Science 12:96.

Davis AK, Chi J, Bradley C, and Altizer S. 2012. The redder the better: wing color predicts flight performance in monarch butterflies. PLoS ONE 7:e41323.

Dijkstra K-DB, and Lewington R. 2006. Field Guide to the Dragonflies of Britain and Europe.

Gillingham, UK: British Wildlife Publishing.

Dudley R. 1990. Biomechanics of insect flight in neotropical butterflies: morphometrics and kinematics. Journal of Experimental Biology 150:37-53.

Dudley R. 2002. The Biomechanics of Insect Flight. Princeton: Princeton University Press.

Ellington CP. 1984. The aerodynamics of hovering insect flight: II. Morphological parameter.

Philosophical Transactions of the Royal Society: Series B (Biological Sciences) 305:17-40.

Ennos AR. 1989. The effect of size on the optimal shapes of gliding insects and seeds. Journal of Zoology 219:61-69. 
301 Hammer Ø, Harper DAT, and Ryan PD. 2001. PAST: Paleontological Statistics Software Package for

302 Education and Data Analysis. Paleontologica Electronica 4:9.

303 Hassall C. 2013. Time stress and temperature explain continental variation in damselfly body size.

304 Ecography 36:894-903.

305 Hassall C. 2014. Continental variation in wing pigmentation in Calopteryx damselflies is related to the 306 presence of heterospecifics. PeerJ 2:e438.

307 Hassall C, and Thompson DJ. 2008. The impacts of environmental warming on Odonata: a review.

308 International Journal of Odonatology 11:131-153.

309 Hassall C, and Thompson DJ. 2010. Accounting for recorder effort in the detection of range shifts from

310 historical data. Methods in Ecology and Evolution 1:343-350.

311 Hassall C, Thompson DJ, French GC, and Harvey IF. 2007. Historical changes in the phenology of

312 British Odonata are related to climate. Global Change Biology 13:933-941.

313 Hassall C, Thompson DJ, and Harvey IF. 2008. Wings of Coenagrion puella vary in shape at the northern

314 range margin (Odonata: Coenagrionidae). International Journal of Odonatology 11:35-41.

315 Hassall C, Thompson DJ, and Harvey IF. 2009. Variation in morphology between core and marginal

316 populations of three British damselflies. Aquatic Insects 31:187-197.

317 Haylock MR, Hofstra N, Klein Tank AMG, Klok EJ, Jones PD, and New M. 2008. A European daily

318 high-resolution gridded dataset of surface temperature and precipitation. Journal of Geophysical Research

319 Series D, Atmospheres 113.

320 Hickling R, Roy DB, Hill JK, Fox R, and Thomas CD. 2006. The distributions of a wide range of

321 taxonomic groups are expanding polewards. Global Change Biology 12:1-6.

322 Hill JK, Thomas CD, and Blakeley DS. 1999. Evolution of flight morphology in a butterfly that has

323 recently expanded its geographic range. Oecologia 121:165-170.

324 Hughes CL, Dytham C, and Hill JK. 2007. Modelling and analysing evolution of dispersal in populations 325 at expanding range boundaries. Ecological Entomology 32:437-445. 
326 Jenkins DG, Brescacin CR, Duxbury CV, Elliott JA, Evans JA, Grablow KR, Hillegass M, Lyon BN,

327 Metzger GA, Olandese ML, Pepe D, Silvers GA, Suresch HN, Thompson TN, Trexler CM, Williams GE,

328 Williams NC, and Williams SE. 2007. Does size matter for dispersal distance? Global Ecology and

329 Biogeography 16:415.

330 Johansson F. 2003. Latitudinal shifts in body size of Enallagma cyathigerum (Odonata). Journal of

331 Biogeography 30:29-34.

332 Johansson F, Söderquist M, and Bokma F. 2009. Insect wing shape evolution: independent effects of

333 migratory and mate guarding flight on dragonfly wings. Biological Journal of the Linnean Society

$33497: 362-372$.

335 Lehmann FO. 1999. Ambient temperature affects free-flight performance in the fruit fly Drosophila

336 melanogaster. Journal of Comparative Physiology B 169:165-171.

337 Marden JH. 1987. Maximum lift production during take-off in flying animals. Journal of Experimental

338 Biology 130:235-258.

339 Marden JH. 1989. Bodybuilding dragonflies: costs and benefits of maximizing flight muscle.

$340 \quad$ Physiological Zoology 62:505-521.

341 Marden JH. 1995. Large-scale changes in thermal sensitivity of flight performance during adult

342 maturation in a dragonfly. Journal of Experimental Biology 198:2095-2102.

343 Marden JH, and Rollins RA. 1994. Assessment of energy reserves by damselflies engaged in aerial

344 contests for mating territories. Animal Behaviour 48:1023-1030.

345 Marden JH, and Waage JK. 1990. Escalated damselfly contests are energetic wars of attrition. Animal

346 Behaviour 39:954-959.

347 McLachlan AJ. 1986. Sexual dimorphism in midges: strategies for flight in the rain-pool dweller

348 Chironomus imicola (Diptera: Chironomidae). Journal of Animal Ecology 55:261-267.

349 Merckx T, and Van Dyck H. 2006. Landscape structure and phenotypic plasticity in flight morphology in 350 the butterfly Pararge aegeria. Oikos 113:226-232. 
351 Mönkkönen M. 1995. Do migrant birds have more pointed wings? A comparative study. Evolutionary

352 Ecology 9:520-528.

353 Norberg UM. 1989. Vertebrate Flight, Mechanics, Physiology, Morphology, Ecology and Evolution.

354 Berlin: Springer-Verlag.

355 Outomuro D, Bokma F, and Johansson F. 2012. Hind wing shape evolves faster than front wing shape in

356 Calopteryx damselflies. Evolutionary Biology 39:116-125.

357 Plaistow S, and Siva-Jothy MT. 1996. Energetic constraints and male mate-securing tactics in the

358 damselfly Calopteryx splendens xanthostoma (Charpentier). Proceedings of the Royal Society: Series B

359 (Biological Sciences) 263:1233-1238.

360 Rasband WS. (1997-2007) ImageJ. $<\underline{\mathrm{http}} / / / \mathrm{rsb}$. info.nih.gov/ij/ $>$.

361 Rohlf FJ. 2008. tpsDig, digitize landmarks and outlines, version 2.12. State University of New York at

362 Stony Brook: Department of Ecology and Evolution.

363 Rüppell G. 1989. Kinematic analysis of symmetrical flight manoeuvres of Odonata. Journal of

364 Experimental Biology 144:13-42.

365 Sadeghi S, Adriaens D, and Dumont HJ. 2009. Geometric morphometric analysis of wing shape variation

366 in ten European populations of Calopteryx splendens (Harris, 1782) (Zygoptera: Odonata).

367 Odonatologica 38:343-360.

368 Siva-Jothy MT. 1999. Male wing pigmentation may affect reproductive success via female choice in a

369 calopterygid damselfly (Zygoptera). Behaviour 136:1365-1377.

370 Stalker HD. 1980. Chromosome studies in wild populations of Drosophila melanogaster. II. Relationship

371 of inversion frequenceis to latitude, season, wing-loading and flight activity. Genetics 95:211-223.

372 Taylor PD, and Merriam G. 1995. Wing morphology of a forest damselfly is related to landscape

373 structure. Oikos 73:43-48.

374 Thomas CD, Hill JK, and Lewis OT. 1998. Evolutionary consequences of habitat fragmentation in a

375 localized butterfly. Journal of Animal Ecology 67:485-497. 
376 Travis JMJ, and Dytham C. 1999. Habitat persistence, habitat availability and the evolution of dispersal.

377 Proceedings of the Royal Society: Series B (Biological Sciences) 266:723-728.

378 Vandewoestijne S, and Van Dyck H. 2011. Flight morphology along a latitudinal gradient in a butterfly:

379 do geographic clines differ between agricultural and woodland landscapes? Ecography 34:876-886.

380 Vargas A, Mittal R, and Dong H. 2008. A computational study of the aerodynamic performance of a

381 dragonfly wing section in gliding flight. Bioinspiration \& Biomimetics 3:1-13.

382 Vogel S. 1957. Flight in Drosophila: III. Aerodynamic characteristics of fly wing and wing models.

383 Journal of Experimental Biology 46:431-443.

384 Waage JK. 1973. Reproductive behavior and its relation to territoriality in Calopteryx maculata

385 (Beauvois) (Odonata: Calopterygidae). Behaviour 47:240-256.

386 Wakeling JM, and Ellington CP. 1997a. Dragonfly flight. II. Velocities, accelerations and kinematics of

387 flapping flight. Journal of Experimental Biology 200:557-582.

388 Wakeling JM, and Ellington CP. 1997b. Dragonfly flight. III. Lift and power requirements. Journal of

389 Experimental Biology 200:583-600.

390 Wakeling JM, and Ellington CP. 1997c. Dragonfly flight: I Gliding flight and steady-state aerodynamic

391 forces. Journal of Experimental Biology 200:543-556.

392 Wickman PO. 1992. Sexual selection and butterfly design - a comparative study. Evolution 46:1525-

3931536.

394 Wootton RJ. 1992. Functional morphology of insect wings. Annual Review of Entomology 37:113-140. 
Figure 1 (on next page)

Calopteryx maculata sampling sites

(A) The geographic distribution of Calopteryx maculata (light shaded area) in relation to the 34 locations at which specimens were collected. (B) Shows the geographical variation in the maximum temperature of the warmest month across the region. 
Figure 2 (on next page)

Wing landmarks for Calopteryx maculata

This figure shows the locations of 14 landmarks on the wing of Calopteryx maculata that were digitised and then analysed using geometric morphometrics to describe wing shape 


\section{PeerJ Reviewing Manuscript}

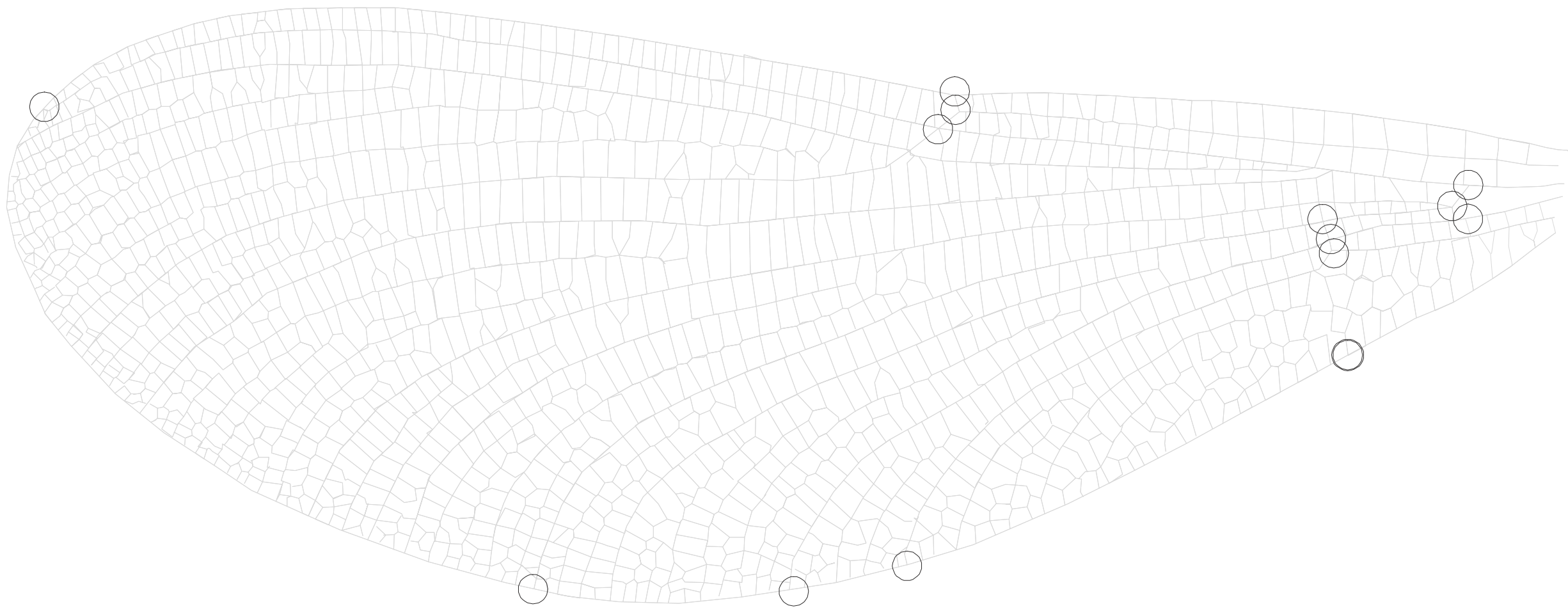


Figure 3 (on next page)

Shape variation in Calopteryx maculata wings

Deformation plots showing the effect of increasing the value of each principal component on the relative locations of wing landmarks. Arrows indicate the direction and extent of change. Percentages are the percentage of variation explained by each principal component for fore and hind wings, respectively. 
Forewing

Hindwing

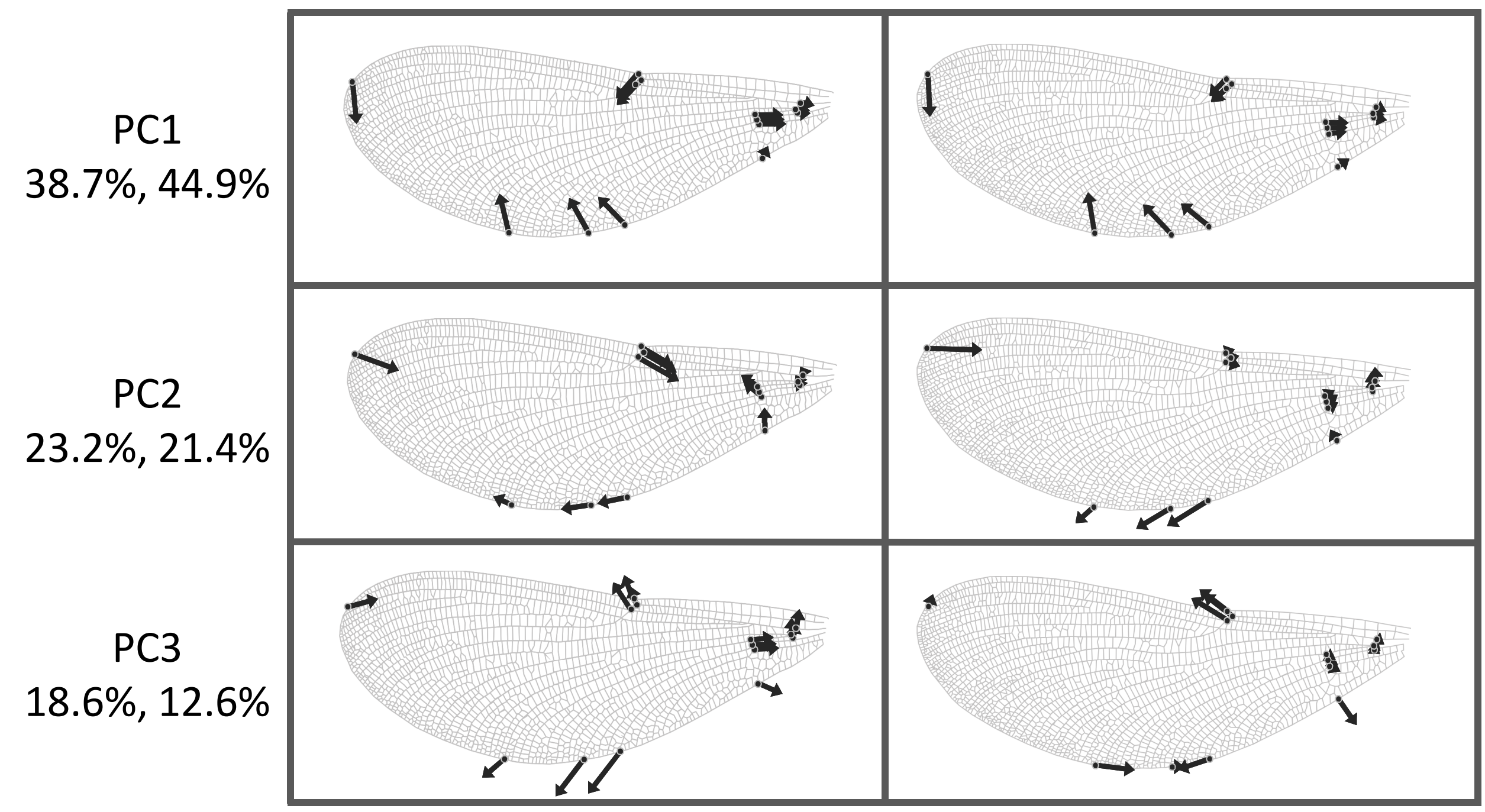


Figure 4 (on next page)

Aspect ratio vs. geometric morphometrics

Relationship between aspect ratio and the first principal component describing variation in wing shape for fore (closed symbols, solid line) and hind wings (open symbols, dotted line) in Calopteryx maculata. Points are mean values from each of 34 sampling sites for both variables. 


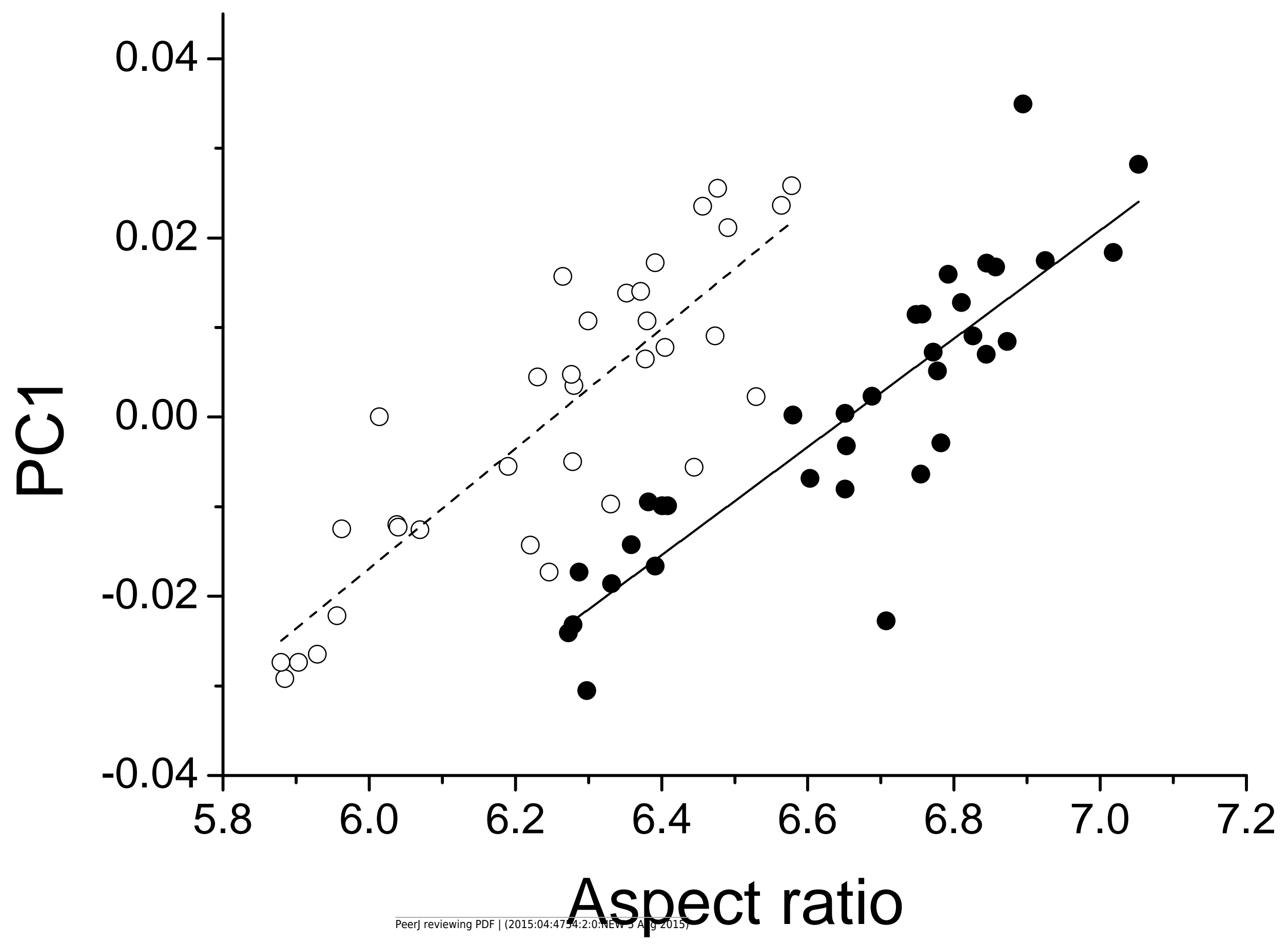


Figure 5(on next page)

Aspect ratio variation in Calopteryx maculata

Distribution of fore wing aspect ratio values for Calopteryx maculata males across the species range (light shaded area) in North America. 


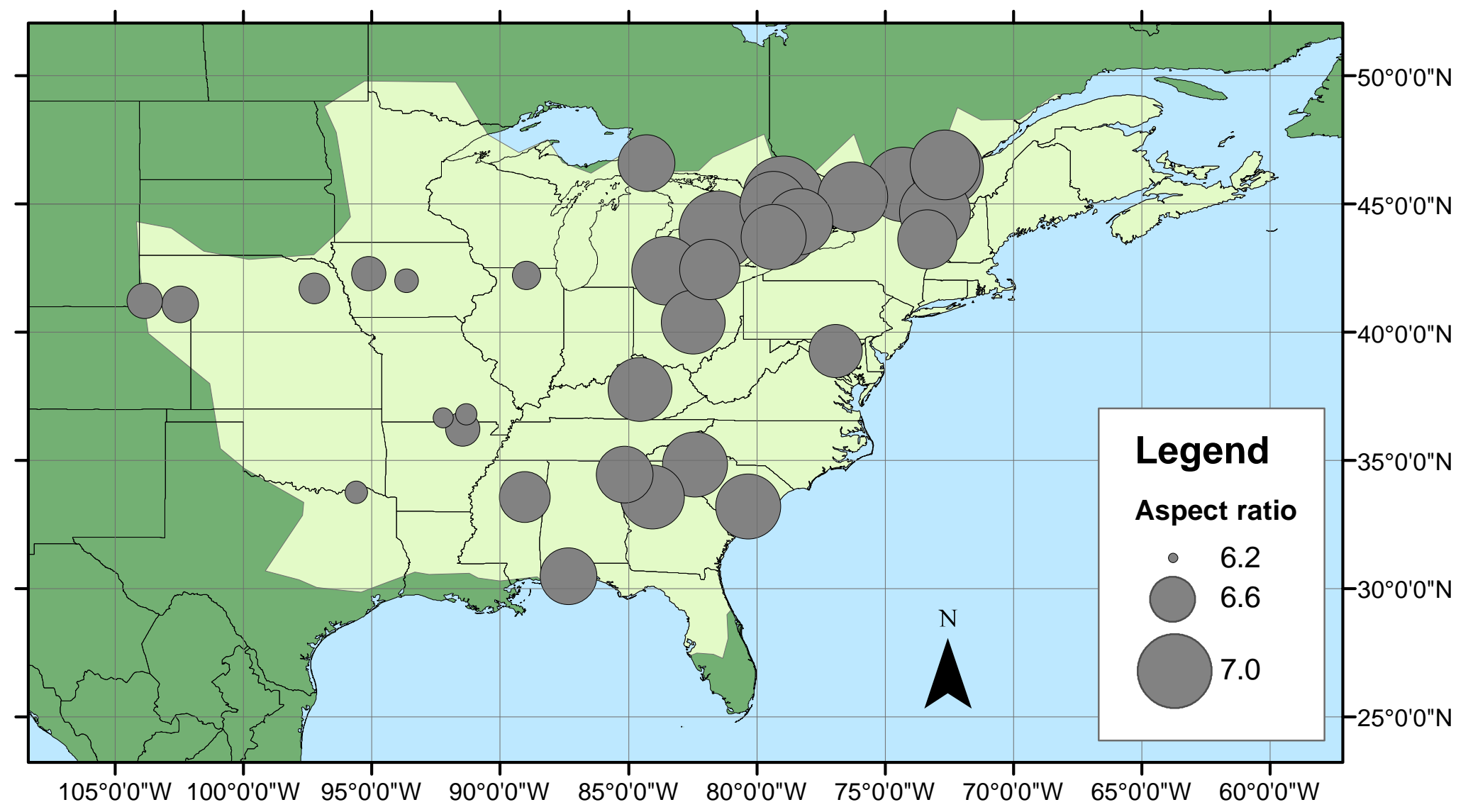


Figure $\mathbf{6}$ (on next page)

Aspect ratio in Calopteryx maculata in relation to latitude, longitude, and temperature

Relationships between fore wing aspect ratio in Calopteryx maculata and (A) latitude, (B) longitude, and $(C)$ the maximum temperature of the warmest month. Points are mean values from each of 34 sampling sites for both variables. 


\section{Table 1 (on next page)}

Sampling data for Calopteryx maculata

Sampling site locations, sample sizes and aspect ratios of wings of male Calopteryx maculata. "Measurements" gives the sample size for the total number of measured specimens, "Geo Morph" gives the sample sizes used in the geometric morphometric analysis ( $\mathrm{N}_{\text {fore }}=$ sample size for fore wings, $\mathrm{N}_{\text {hind }}=$ sample size for hind wings). 
Measurements Geo Morph

\begin{tabular}{|c|c|c|c|c|c|c|c|c|c|c|c|}
\hline & & & & & Fore wing & Hind wing & & & & & \\
\hline Ontario & Blakeney Falls & 45.268 & -76.250 & $31 / 05 / 10$ & $6.845( \pm 0.044)$ & $6.392( \pm 0.037)$ & 23 & 23 & 23 & 10 & 10 \\
\hline Ontario & Dorset & 45.271 & -78.960 & $31 / 07 / 10$ & $7.053( \pm 0.075)$ & $6.564( \pm 0.069)$ & 7 & 6 & 7 & 6 & 7 \\
\hline Ontario & Heber Down & 43.941 & -78.988 & $08 / 06 / 10$ & $6.845( \pm 0.034)$ & $6.380( \pm 0.034)$ & 20 & 20 & 20 & 10 & 10 \\
\hline Ontario & North Bay & 44.947 & -79.471 & $20 / 06 / 10-21 / 06 / 10$ & $6.811( \pm 0.019)$ & $6.372( \pm 0.019)$ & 84 & 84 & 84 & 10 & 10 \\
\hline Ontario & Peterborough & 44.315 & -78.343 & $15 / 06 / 10$ & $6.792( \pm 0.048)$ & $6.352( \pm 0.052)$ & 20 & 20 & 20 & 10 & 10 \\
\hline Ontario & Ridgetown & 42.439 & -81.831 & $11 / 07 / 10$ & $6.707( \pm 0.048)$ & $6.280( \pm 0.039)$ & 18 & 18 & 18 & 10 & 10 \\
\hline Quebec & Dunany & 45.758 & -74.304 & $25 / 06 / 10$ & $6.925( \pm 0.036)$ & $6.457( \pm 0.040)$ & 15 & 14 & 15 & 10 & 10 \\
\hline Quebec & Shawinigan & 46.514 & -72.679 & $27 / 06 / 10$ & $6.857( \pm 0.032)$ & $6.491( \pm 0.059)$ & 33 & 26 & 25 & 10 & 10 \\
\hline Arkansas & Smithville & 36.235 & -91.470 & $22 / 05 / 10-07 / 08 / 10$ & $6.382( \pm 0.027)$ & $6.014( \pm 0.028)$ & 35 & 35 & 33 & 10 & 10 \\
\hline Florida & 8 Mile Creek & 30.483 & -87.326 & $26 / 06$ & $6.653( \pm 0.045)$ & $6.278( \pm 0.039)$ & 20 & 19 & 19 & 10 & 10 \\
\hline Georgia & Conyers Monastery & 33.584 & -84.073 & $04 / 08$ & $6.755( \pm 0.049)$ & $6.331( \pm 0.045)$ & 11 & 11 & 11 & 10 & 10 \\
\hline Georgia & Rome & 34.443 & -85.150 & $18 / 06 / 10-27 / 06 / 10$ & $6.651( \pm 0.041)$ & $6.221( \pm 0.036)$ & 20 & 19 & 15 & 10 & 10 \\
\hline Illinois & Rockford & 42.211 & -88.976 & $17 / 07 / 10$ & $6.332( \pm 0.040)$ & $5.956( \pm 0.040)$ & 20 & 20 & 20 & 10 & 10 \\
\hline Mississippi & Starkville & 33.567 & -89.041 & $05 / 07 / 10$ & $6.580( \pm 0.035)$ & $6.190( \pm 0.031)$ & 26 & 26 & 24 & 10 & 10 \\
\hline Missouri & Eleven Point River & 36.793 & -91.331 & $05 / 06 / 10$ & $6.279( \pm 0.047)$ & $5.885( \pm 0.042)$ & 12 & 12 & 12 & 10 & 10 \\
\hline Missouri & White River & 36.654 & -92.230 & $05 / 06 / 10$ & $6.273( \pm 0.028)$ & $5.903( \pm 0.028)$ & 25 & 24 & 21 & 10 & 10 \\
\hline Nebraska & Chappell & 41.083 & -102.467 & $30 / 06 / 10$ & $6.408( \pm 0.065)$ & $6.070( \pm 0.061)$ & 6 & 6 & 6 & 6 & 6 \\
\hline Nebraska & Kimball & 41.232 & -103.843 & $01 / 07 / 10$ & $6.401( \pm 0.030)$ & $6.038( \pm 0.030)$ & 32 & 32 & 32 & 10 & 10 \\
\hline Nebraska & Leigh & 41.701 & -97.247 & $21 / 06 / 10$ & $6.359( \pm 0.034)$ & $5.963( \pm 0.034)$ & 25 & 23 & 22 & 10 & 10 \\
\hline Ohio & Mt Vernon & 40.405 & -82.487 & $16 / 06 / 10$ & $6.748( \pm 0.023)$ & $6.300( \pm 0.025)$ & 40 & 39 & 39 & 10 & 10 \\
\hline South Carolina & Four Holes Swamp & 33.212 & -80.348 & $14 / 07 / 10$ & $6.782( \pm 0.059)$ & $6.445( \pm 0.046)$ & 21 & 21 & 21 & 10 & 10 \\
\hline South Carolina & Little Creek & 34.842 & -82.402 & $15 / 07 / 10$ & $6.777( \pm 0.040)$ & $6.529( \pm 0.050)$ & 29 & 28 & 28 & 10 & 10 \\
\hline Texas & Powderly & 33.753 & -95.605 & $13 / 05 / 10$ & $6.287( \pm 0.033)$ & $5.929( \pm 0.030)$ & 22 & 19 & 18 & 10 & 10 \\
\hline Vermont & Lamoille River & 44.681 & -73.068 & $18 / 06 / 10$ & $6.873( \pm 0.123)$ & $6.473( \pm 0.112)$ & 4 & 4 & 4 & 4 & 4 \\
\hline
\end{tabular}




\begin{tabular}{llrrrrrrrrrr} 
Vermont & West Haven & 43.624 & -73.362 & $24 / 07 / 10$ & $6.688( \pm 0.037)$ & $6.277( \pm 0.035)$ & 17 & 11 & 10 & 10 & 10 \\
Vermont & Winooski River & 46.352 & -72.571 & $04 / 07 / 10-18 / 07 / 10$ & $6.895( \pm 0.034)$ & $6.477( \pm 0.028)$ & 42 & 42 & 41 & 10 & 10 \\
\hline
\end{tabular}

1 


\section{Table 2 (on next page)}

Model selection table

Model fits for linear regression of Bioclim variables ( Haylock et al. 2008 ) on fore and hind wing aspect ratios in Calopteryx maculata. 
Fore wing aspect ratio Hind wing aspect ratio

\begin{tabular}{llrrrrrr}
\hline Variable & Definition & $\operatorname{logLik}$ & AICc & $\Delta$ AICc & logLik & AICc & $\Delta$ AICc \\
\hline BIO5 & Max Temp of Warmest Month & 12.743 & -18.686 & 0.000 & 12.861 & -18.923 & 0.539 \\
BIO2 & Mean Diurnal Range (Mean of monthly (max - min)) & 12.109 & -17.417 & 1.269 & 13.131 & -19.462 & 0.000 \\
BIO10 & Mean Temp of Warmest Quarter & 7.578 & -8.357 & 10.329 & 8.860 & -10.919 & 8.542 \\
BIO3 & Isothermality (BIO2/BIO7) (* 100) & 5.793 & -4.786 & 13.900 & 7.327 & -7.855 & 11.607 \\
BIO1 & Annual Mean Temp & 4.933 & -3.067 & 15.620 & 6.790 & -6.780 & 12.682 \\
BIO11 & Mean Temp of Coldest Quarter & 3.878 & -0.957 & 17.729 & 5.973 & -5.146 & 14.315 \\
BIO8 & Mean Temp of Wettest Quarter & 3.713 & -0.627 & 18.060 & 6.395 & -5.990 & 13.472 \\
BIO6 & Min Temp of Coldest Month & 3.009 & 0.782 & 19.469 & 5.406 & -4.012 & 15.449 \\
BIO7 & Temper Annual Range (BIO5-BIO6) & 2.764 & 1.271 & 19.957 & 6.032 & -5.265 & 14.197 \\
BIO4 & Temp Seasonality (SD *100) & 2.354 & 2.093 & 20.779 & 5.056 & -3.312 & 16.150 \\
BIO9 & Mean Temp of Driest Quarter & 2.289 & 2.223 & 20.909 & 5.050 & -3.301 & 16.161 \\
\hline
\end{tabular}




\section{Table 3 (on next page)}

\section{Final models}

Model performance and parameter estimates for regressions of aspect ratio on longitude, latitude, and the maximum temperature of the warmest month. 


\begin{tabular}{lrrrrrrr}
\hline & Estimate & $\mathrm{SE}$ & $\mathrm{T}$ & $\mathrm{P}$ & $\mathrm{R}^{2}$ & $\mathrm{AICc}$ & $\Delta \mathrm{AICc}$ \\
\hline Intercept & 8.545 & 0.236 & 36.251 & $<0.001$ & 0.660 & -35.2 & 0.00 \\
Longitude & 0.022 & 0.003 & 8.057 & $<0.001$ & & & \\
& & & & & & & \\
Intercept & 8.111 & 0.279 & 29.106 & $<0.001$ & 0.446 & -18.7 & 16.53 \\
Max T warmest month & -0.005 & 0.001 & -5.252 & $<0.001$ & & & \\
& & & & & & & \\
Intercept & 14.648 & 2.771 & 5.286 & $<0.001$ & 0.325 & -10.5 & 24.74 \\
Latitude & -0.434 & 0.142 & -3.048 & 0.005 & & & \\
Latitude $^{2}$ & 0.006 & 0.002 & 3.191 & 0.003 & & & \\
\hline
\end{tabular}

1 